\title{
Perancangan Gelpi (Gelang Piket) Berbasiskan Arduino Uno Sebagai Pengingat Jadwal Piket Siswa Sekolah Dasar
}

\author{
Deny Nusyirwan $^{1}$, Lilis Agustina Sinaga ${ }^{2}$, Prasetya Perwira Putra Perdana ${ }^{3}$ \\ ${ }^{1,2,3}$ Fakultas Teknik, Program Studi Teknik Elektro, Universitas Maritim Raja Ali Haji (UMRAH) \\ ${ }^{1,2,3}$ Jl. Politeknik Senggarang, Tanjungpinang 29100 \\ Email: ${ }^{1}$ denynusyirwan@umrah.ac.id, ${ }^{2}$ agustinalilis04@gmail.com, ${ }^{3}$ pras.perwira@gmail.com
}

\begin{abstract}
ABSTRAK
Sebagian besar dari fasilitas sekolah terdiri dari ruangan-ruangan yang dimanfaatkan untuk kegiatan belajar yang dihadiri oleh siswa dan guru. Ruangan tersebut terdiri dari bangku siswa, meja guru dan beberapa fasilta penunjang seperti lemari untuk menyimpan buku dan hasil karya siswa. Selain sampah yang juga terdapat di dalam kelas, tata letak bangku juga terkadang sudah tidak sesuai setelah jam pelajaran selesai. Sekolah biasanya akan dilengkapi dengan petugas penjaga yang akan membantu dalam hal kebersihan dan kerapian ruangan, namun sudah menjadi kebiasaan di sekolah, wali kelas membentuk jadwal piket yang tediri dari siswa yang bertugas untuk membersihkan dan merapikan ruangan setelah jam pelajaran selesai. Dari hasil pengamatan dapat ditemukan tidak semua siswa yang sudah mendapatkan tugas piket melakukan tugasnya, oleh sebab itu diusulkan sebuah inovasi berbasiskan teknologi yang bernama Gelpi (Gelang Piket) yang berfungsi sebagai pengingat. Gelpi akan diberikan kepada siswa yang mendapatkan jadwal piket di kelas tertentu dan hari tertentu sebelum jam pelajaran terakhir selesai. Teknologi ini mengintegrasikan perangkat mikrokontroler Arduino Uno sebagai pusat pengelolaan informasi, buzzer, LCD yang akan menampilkan pesan dan RTC (Real Time Clock) sebagai pengatur waktu. Penelitian dimulai dengan pendekatan Double Diamand yang diperkenalkan oleh British Design Council, yaitu memulai proses perancangan dengan social research yang bertujuan untuk dapat menghasilkan inovasi berbasis teknologi yang bermanfaat bagi masyarakat setempat. Setelah mendapatkan solusi utama, maka akan dilanjutkan dengan pembuatan sederhana yang akan dipergunakan untuk uji fungsi dan manfaat bersama calon pengguna. Dari hasil pengujian bersama calon pengguna, didapatkan bahwa purwarupa yang berbentuk seperti jam tangan tidak mengganggu siswa, karena siswa pada umumnya sudah mempergunakan jam tangan ketika di sekolah. Fungsi pengingat sangat membantu siswa menghindari kelupaan terkait jadwal piket. Dan pada akhirnya tugas guru akan menjadi lebih mudah karena tidak perlu mengingatkan siswa setiap hari setelah jam pelajaran terahir.
\end{abstract}

Kata Kunci : sekolah; siswa; arduino; buzzer; RTC

\section{ABSTRACT}

Most of the school facilities consist of rooms that are used for learning activities attended by students and teachers. The room consists of a student bench, a teacher's desk and several supporting facilities such as a cupboard to store books and student work. In addition to garbage that is also present in the classroom, the bench layout is also sometimes not suitable after the lesson is over. Schools will usually be equipped with guard officers who will assist in the cleanliness and tidiness of the room, but it has become a habit in school, homerooms form a picket schedule consisting of students who are tasked with cleaning and tidying up the room after class hours. From the results of the observations, it can be found that not all students who have received picket assignments do their job, therefore a technology-based innovation called Gelpi (Picket 
Bracelet) is proposed that serves as a reminder. Gelpi will give to students who get picket schedules in certain classes and certain days before the last lesson hours are completed. This technology integrates Arduino Uno microcontroller devices as a center for information management, buzzer, LCD that will display messages and RTC (Real Time Clock) as a timer. The research began with the Double Diamand Design Process of the United Kingdom Design Council, which began the design process with social research that aims to be able to produce technologybased innovations that benefit the community. After getting the main solution, it will be followed by a simple manufacture that will be used to test the functions and benefits with prospective users. Based on the results of testing with prospective users, obtained from prototype that form watches that are not opened by students, because students in general already use compilation watches at school. A reminder function that is very helpful for students who are opposed to forgetfulness related to picket schedules. And finally the task of the teacher will be easier because there is no need for students every day after the last lesson.

Keywords : school; student; arduino; buzzer; RTC

\section{PENDAHULUAN}

Tugas membersihkan dan merapikan ruangan kelas setelah jam pelajaran berahir merupakan tugas tambahan yang terkadang di berikan oleh wali kelas di sekolah untuk para muridnya dengan tujuan dan harapan untuk menumbuhkan karakter siswa dan siswi pada sekolah dasar untuk bertanggung jawab dan bekerjasama dengan rekan lainnya untuk menjadikan ruangan kelas nyaman dan sehat ketika akan dipergunakan. Untuk membantu siswa dan siswi dalam mengemban tanggung jawab dalam melakukan tugas piketnya, telah dirancang alat sederhana yang dinamanakan Gelang Piket (Picket Bracelet) yang berfungsi sebagai alarm, dimana gelang ini akan bekerja pada saat jam piket tiba.

Penelitian telah dimulai dengan observasi secara langsung di sekolah yang disertai dengan wawancara. Selanjutnya dilakukan tahapan diskusi secara bebas untuk mendapatkan beberapa usulan solusi dari beberapa permasalahan yang ditemukan. Tahapan pembuatan purwarupa sederhana diperlukan untuk mendapatkan bentuk rancangan yang sesuai dengan kebutuhan pengguna, untuk mendapatkan masukan dalam bentuk nyata sebelum dilakukan ujicoba kepada pengguna untuk mendapatkan masukan dalam memperbaiki rancangan sebelumnya (apabila diperlukan). Keseluruhan tahapan ini dikenal Proses Rancangan Rekayasa.

\section{Penelitian terdahulu}

Kesibukan terkadang dapat mengakibatkan seseorang menempatkan barang tidak pada tempatnya, sehingga pada saat dibutuhkan akan sulit ditemukan. Berdasarkan permasalahan ini, maka telah dilakukan penelitian berjudul Reminder Kit Secara Wireless Berbasis Mikrokontroler AVR. Pada perancangan ini menempatkan bagian slave pada peralatan yang dibutuhkan, sedangkan pada bagian master akan dipegang oleh pengguna. Adapun komponen yang dipergunakan adalah mikrokontroler dengan IC ATMega8L, Modul transceiver data via gelombang radio, dan buzzer [1].

Teknologi saat ini sudah menjadi kebutuhan di kehidupan keseharian, diantaranya adalah penerapan teknologi untuk keamanan rumah. Pemasangan 
kamera CCTV sudah menjadi kebutuhan untuk pemilik yang sering bepergian. Namun sayangnya, teknologi tersebut merupakan sebuah usaha untuk melakukan penanganan kejadian sehingga tidak mampu untuk menunda atau menghindari peristiwa. Berdasarkan permasalahan tersebut, sebuah penelitian dengan judul Aplikasi Alarm Anti Maling Berbasis Mikrokontroler AT Mega 8535 telah melakukan sebuah inovasi teknologi untuk mengirimkan informasi berupa pesan singkat dan panggilan ke nomor yang sudah didaftarkan apabila terdapat objek yang mencurigakan di dalam rumah. Selain menggunakan mikrokontroler untuk mengatur input dan output, juga digunakan sensor PIR dan sensor Ultrasonik untuk mendeteksi keberadaan objek yang mencurigakan dan Modem untuk komunikasi [2]

Pencurian pada umumnya terjadi ketika pemilik tidak berada di rumah ataupun ketika sedang istirahat di malam hari. Keadaan rumah kosong dan gelap menjadi faktor utama terjadinya peristiwa pencurian. Sebuah penelitian yang berjudul Aplikasi Sensor Cahaya Untuk Alarm Anti Pencuri telah merencang sebuah inovasi berbasis teknologi mikrokontroler IC LM7805 dan sensor LDR. Sensor LDR akan terkena cahaya laser pointer dan apabila cahaya tersebut terhalang oleh benda, maka akan mengaktifkan LED dan panggilan kepada nomor telpon seluler pemilik rumah yang sudah didaftarkan [3].

Tidak meminum obat yang sudah disediakan, dapat terjadi karena ketidak sengajaan seperti tertidur dan kelupaan. Oleh sebab itu, pada penelitian yang berjudul Prototipe kotak pengingat minum obat telah menghasilkan sebuah inovasi teknologi sederhana yang bekerja dengan sistem buzzer sebagai pengingat. Waktu dapat diatur oleh pasien secara mudah dan akan berhenti apabila tombol power ditekan. Mikrokontroler Arduino Nano sebagai pengatur input dan output, sensor suhu untuk menjaga obat tidak rusak, LCD untuk menampilkan suhu didalam kotak, RTC untuk mengatur waktu minum obat dan buzzer sebagai penanda. [4]

\section{METODE KEGIATAN}

Peranan penting bagi ilmuwan pada perguruan tinggi adalah berperan serta dalam mendidik masyarakat tentang metode dan hasil dari proses ilmiah [5], oleh sebab itu diperlukan sebuah tahapan perancangan rekayasa untuk dapat menemukan inovasi berbasiskan teknologi yang memiliki fungsi tepat dan mudah untuk dipergunakan. Jika pada masa lalu para rekayasawan telah dievaluasi berdasarkan pada keterampilan teknis saja, maka kedepannya akan dibutuhkan lebih banyak lagi rekayasawan yang mampu bekerja dengan pendekatan yang lebih sistemik dan strategis untuk skala yang lebih besar [6].

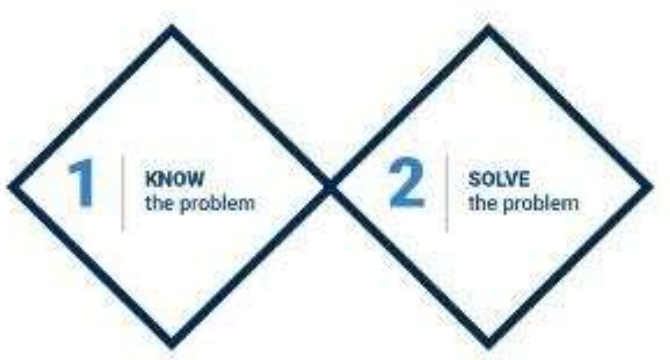

Gambar 1. Tahapan pada Proses Desain Rekayasa [7] 
Proses Desain Rekayasa adalah merupakan kumpulan tahapan didalam menghasilkan inovasi dengan berpusat kepada pengguna. Tahapan ini diawali dengan proses etnografi hingga menghasilkan sebuah purwarupa sederhana yang merupakan sebuah konsep solusi dari permasalahan utama yang dihasilkan untuk memenuhi kebutuhan di masyarakat.

Proses Desain Rekayassa yang dikenal saat ini adalah pendekatan dengan Double Diamand Concept, yang telah diperkenalkan oleh Bristish Design Council. Proses ini memiliki 4 tahapan utama, dimana pada tahapan awal adalah observasi secara luas di masyarakat pada suatu daerah untuk dapat menemukan permasalahan-permasalahan secara luas, adapun pada tahapan kedua adalah proses pengerucutan permasalahan dengan melakukan pemilihan terhadap permasalahan utama, selanjutnya pada tahapan ketiga adalah proses berpikir luas untuk mampu mengembangkan ide-ide sebagai solusi terhadap permasalahan utama yang sudah ditentukan, dan pada tahapan terakhir adalah menentukan solusi utama dari keseluruhan ide yang sudah disampaikan sebelumnya dengan tujuan untuk dapat dilanjutkan kepada tahapan yang sudah memerlukan pembiayaan yaitu pembuatan purwarupa dan pengujian terhadap calon pengguna untuk mendapatkan masukan untuk perbaikan inovasi nantinya, lihat Gambar 1.

\section{Proses Etnografi}

Rekayasa dan pemasaran adalah dua bagian yang sangat diperlukan dan berkaitan dalam proses penelitian ketika pengembangan produk untuk menghasilkan inovasi berbasis teknologi. Bidang tersebut akan saling melengkapi karena memiliki luaran dan tujuan yang berbeda. Peneliti untuk bidang rekayasa sangat ingin mengetahui apa yang sangat dibutuhkan oleh masyarakat yang sedang diobservasi dan bagaimana sebenarnya pengguna akan menggunakan inovasi yang akan dipersiapkan. Sedangkan untuk peneliti di bidang pemasaran ingin mengetahui apa yang akan cepat terjual kepada pengguna, dan mempelajari bagaimana pengguna membuat keputusan pembelian. Pada akhirnya, dengan orientasi yang berbeda ini akan mengarahkan kedua kelompok tersebut untuk mengembangkan metode penelitian dengan perdekatan yang berbeda pula. Rekayasawan akan cenderung menerapkan metode observasi dengan pendekatan secara kualitatif untuk dapat mempelajari orang secara mendalam, memahami bagaimana mereka melakukan kegiatan dengan memperhatikan peran faktor lingkungan. [8]. Metode pendekatan ini akan sangat memakan waktu, sehingga di dalam penelitian ini hanya memeriksa sejumlah kecil orang. Lokasi penelitian dilakukan di SDN 003 Binaan Tanjungpinang, Provinsi Kepulauan Riau, lihat Gambar 2.

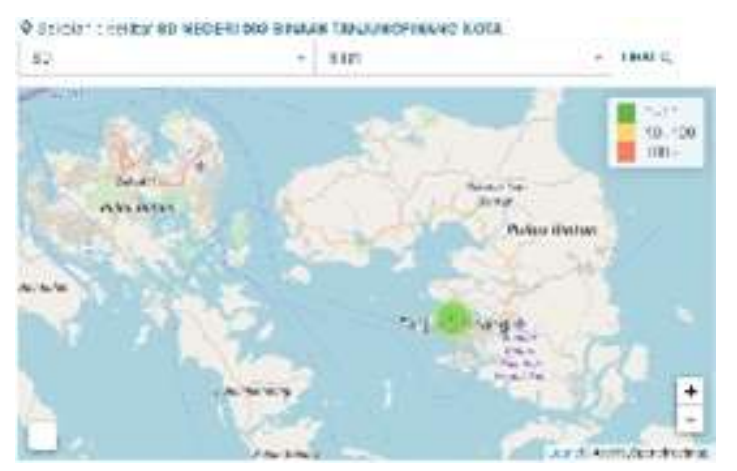

Gambar 2. Lokasi SDN 003 Binaan Tanjung pinang [9] 
Langkah awal dari Proses Desain Rekayasa, yang merupakan aktivitas pegamatan atau observasi secara langsung ke masyarakat di suatu daerah untuk mendapatkan data yang akurat sehingga mampu menghasilkan sebuah solusi yang tepat.

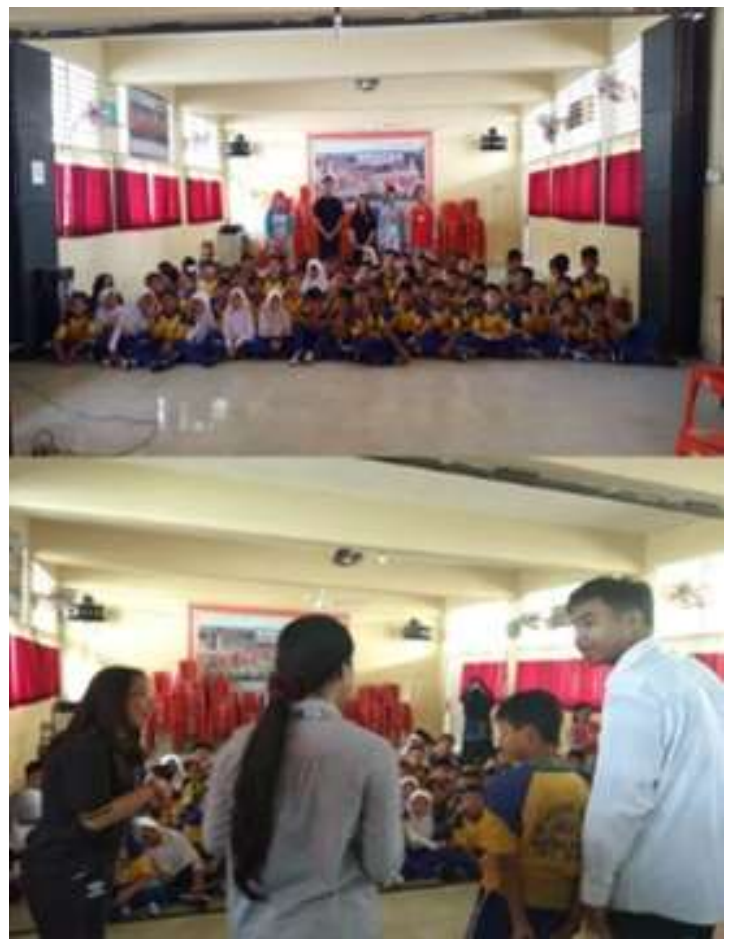

Gambar 3. Suasana di SDN 003 Binaan Tanjung pinang

Pada Gambar 3 menampilkan keadaaan SDN 003 Binaan Tanjung pinang sebagai lokasi untuk mendapatkan data-data yang di perlukan guna menghasilkan inovasi teknologi. Metode etnografi yang diterapkan pada penelitian ini adalah peneliti sebagai peserta, dimana kelompok yang sedang diteliti mengetahui tentang keberadaan peneliti, namun peneliti tidak ikut serta melakukan kegiatan dan aktifitas didalam kelompok yang sedang diteliti [10]. Pada Gambar 4 memperlihatkan peneliti melakukan proses pengumpulan informasi-informasi melalui siswa mengenai permasalahan di SDN 003 Binaan Tanjung pinang.

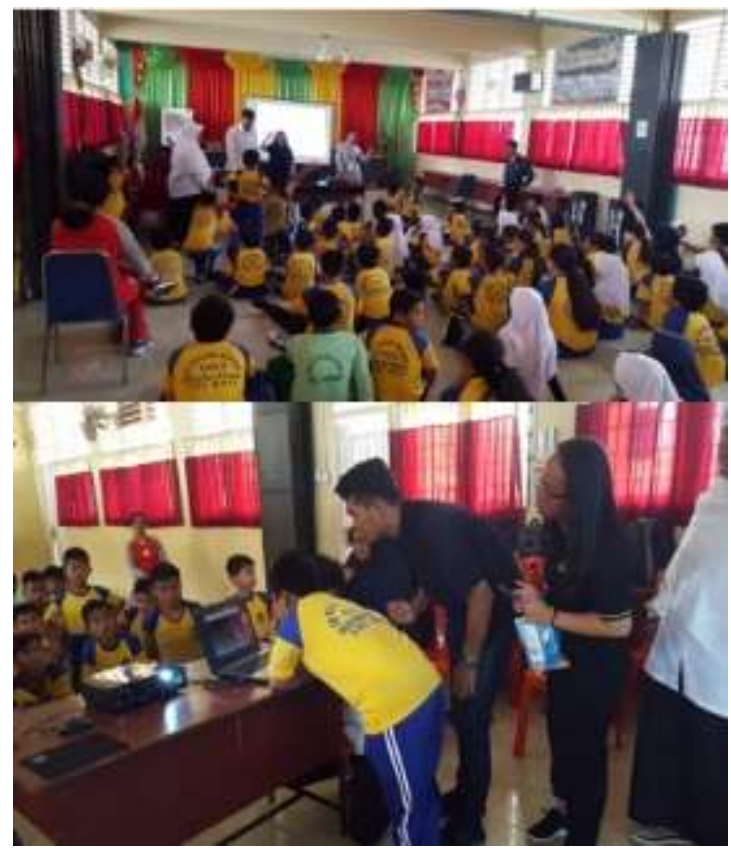

Gambar 4. Proses Etnografi di Sekolah

\section{KARYA UTAMA}

Sistem kerja Gelpi ini menggunakan mikrokontroler Arduino Uno ATmega 328, RTC sebagai pengatur waktu, LCD 16x2 yang nantinya akan memunculkan tulisan "Piket (nama hari), (Nama Siswa yang piket)".

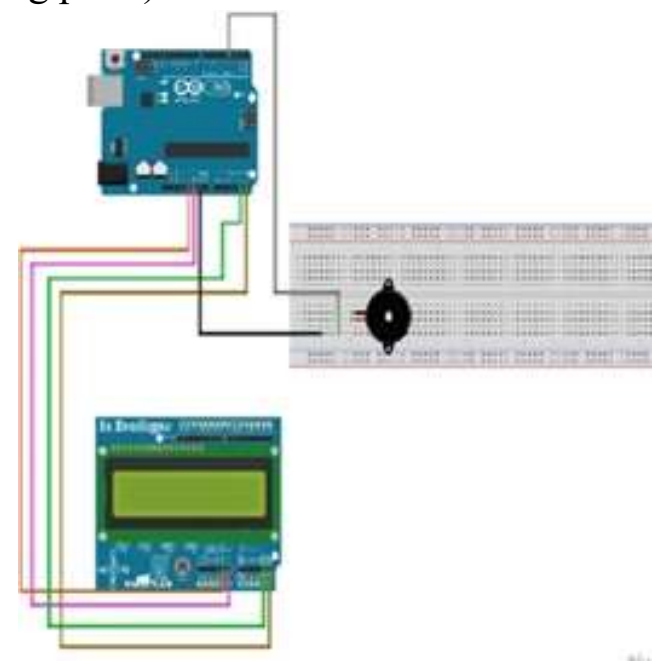

Gambar 5. Rangkaian elektronika sistem Gelang Piket 
Apabila sudah dilakukan penyesuaian waktu, maka pada waktu yang sudah di tentukan nantinya buzzer akan berbunyi dan pada LCD 16x2 akan memunculkan tulisan "Piket (nama hari), (Nama Siswa yang piket)", lihat Gambar 5.

\subsection{Komponen purwarupa}

Adapun komponen yang diperlukan untuk pembuatan purwarupa adalah sebagai berikut

\subsection{Arduino UNO R3}

Arduino Uno R3 adalah merupakan sebuah mikrokontroller yang akan memproses input yang diberikan melalui bahasa pemograman open source sehingga akan menghasilkan output. Dengan menghubungkan Arduino dengan mempergunakan kabel USB ke komputer maka software Arduino sudah bisa untuk memprogram chip ATmega328, lihat

\section{Gambar 6.}

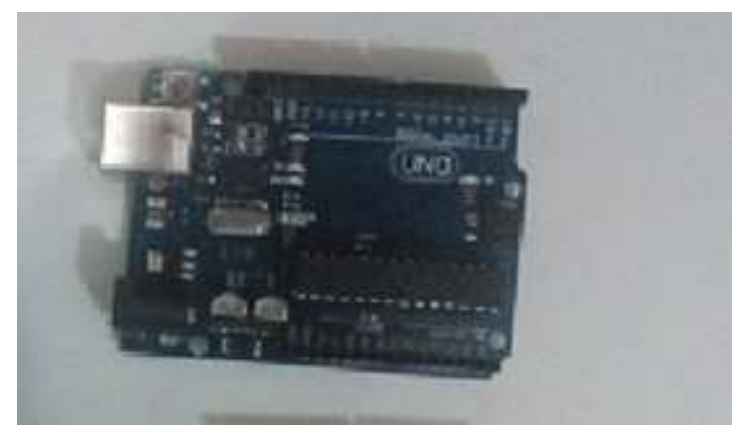

Gambar 6. Arduino Uno

\subsection{Breadboard}

Breadboard sering dipergunakan oleh para pemula elektronika untuk melakukan uji coba rangkaian. Bentuk dari Breadboard ini akan memudahkan komponen untuk dipasang dan dilepas kembali tanpa perlu melakukan penyolderan. Dengan kemudahan ini, maka akan mempermudah melakukan uji coba untuk beberapa jenis rangkaian karena tidak perlu membeli komponen lagi, lihat Gambar 7.

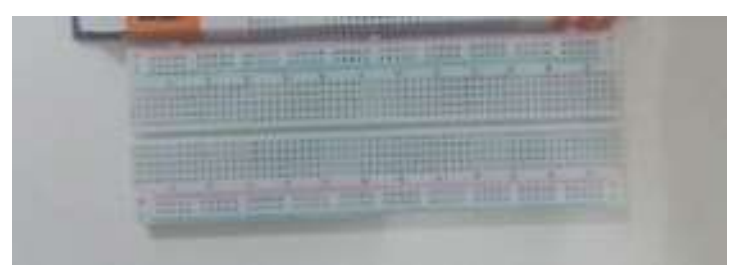

Gambar 7. BreadBoard

\subsection{Kabel jumper}

Kabel jumper adalah kabel yang di pergunakan untuk menghubungkan satu komponen dengan komponen lain ataupun menghubungkan jalur rangkaian yang terputus pada breadboard, lihat Gambar 8.

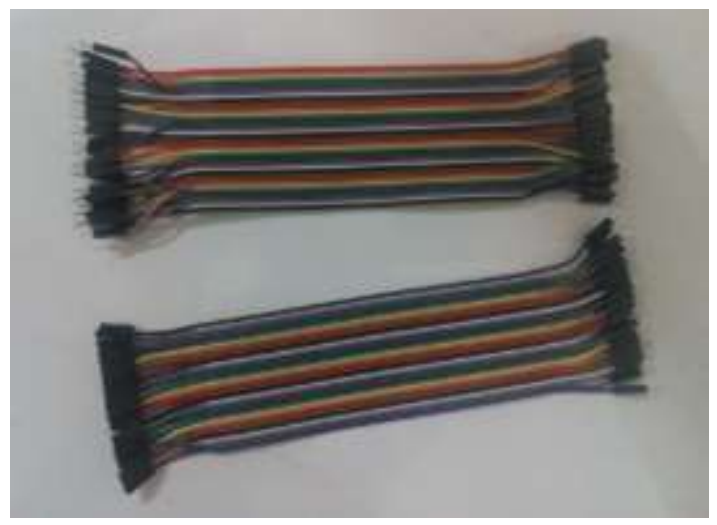

Gambar 8. Kabel Jumper

\subsection{Liquid Cristal Display (LCD)}

LCD adalah sebuah komponen elektronika yang dipergunakan untuk menampilkan tulisan, karakter dan huruf, LCD menggunakan kristal cair sebagai penampil utama. Dalam modul LCD terdapat mikrokontroller yang berfungsi sebagai pengendali tampilan karakter dilengkapi dengan memori dan register. Juga terdapat pin, yang salah satunya berfungsi untuk jalur untuk memberikan data karakter yang ingin ditampilkan, lihat Gambar 9. 


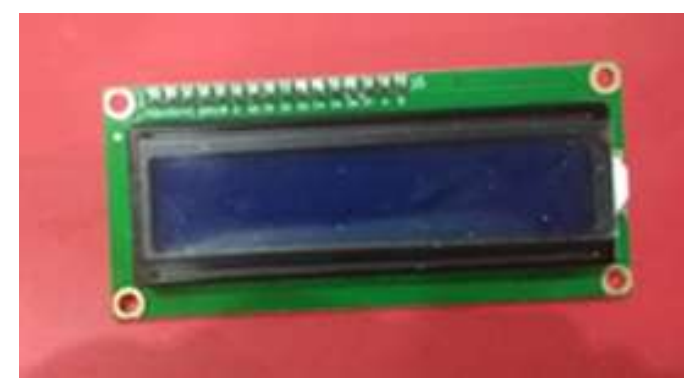

Gambar 9. Liquid Cristal Display

\subsection{I2C Serial}

I2C Serial adalah modul LCD yang di kendalikan secara serial sinkron dengan protocol I2C (Inter Integratred Circuit). Penggunakan I2C Serial pada LCD dapat menghemat jumlah pin yang tersedia di dalam arduino dan membuat sketch pemrograman menjadi simple serta dapat menjaga LCD agar tidak cepat rusak, lihat

\section{Gambar 10.}

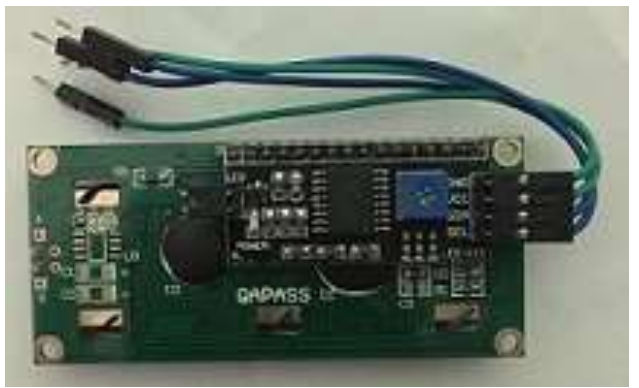

Gambar 10 . I2C

\subsection{Buzzer}

Buzzer adalah sebuah komponen yang akan menghasilkan suara melalui perubahan getaran listrik menjadi suara, lihat Gambar 11.

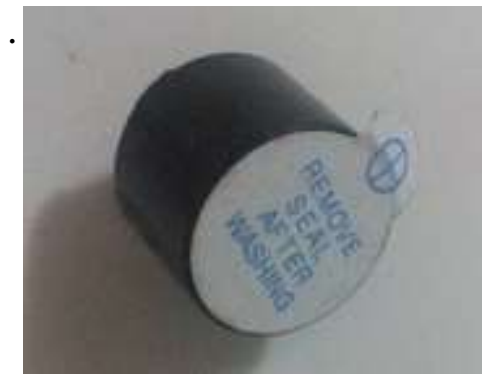

Gambar 11. Buzzer

\subsection{Real Time Clock / RTC}

Real Time Clock / RTC adalah sebuah modul/ kit yang berfungsi untuk menjalankan fungsi waktu dan kalender secara realtime berbasis DS1307 dengan menggunakan backup supply berupa battery, lihat Gambar 12.

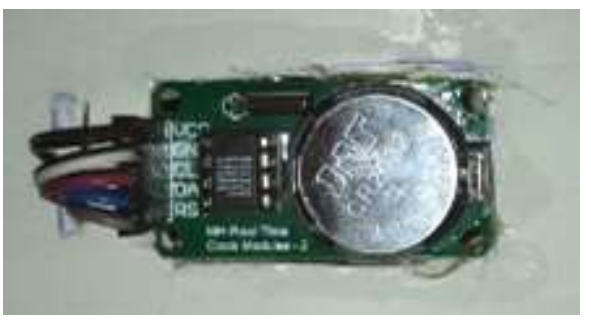

Gambar 12. Real Time Clock

\section{ULASAN KARYA}

Tahapan selanjutnya adalah curahan gagasan atau Brainstorming terhadap permasalahan yang ditemukan di sekolah dari hasil observasi, dimana semua permasalahan yang ditemukan akan di dokumentasikan secara bersamaan. Proses ini adalah merupakan tahapan yang penting, karena sangat diharapkan bahwa dari permasalahan yang ditemukan akan didapatkan solusi yang merupakan solusi yang dibutuhkan, bukan solusi yang diminta oleh calon pengguna. Pola penyampaian gagasan secara bebas juga akan sangat diperlukan untuk memotivasi peneliti agar mampu berpikir inovatif dan kreatif. Curahan gagasan yang bersifat luas ini adalah merupakan pondasi bagi rekayasawan untuk mampu menghasilkan sebuah inovasi yang berbasiskan teknologi. Hal ini sering dipahami dengan $\mathrm{T}$ concept, dimaksudkan bahwa inovasi yang dihasilkan oleh rekayasawan akan memiliki pengaruh yang luas dan mendalam. 


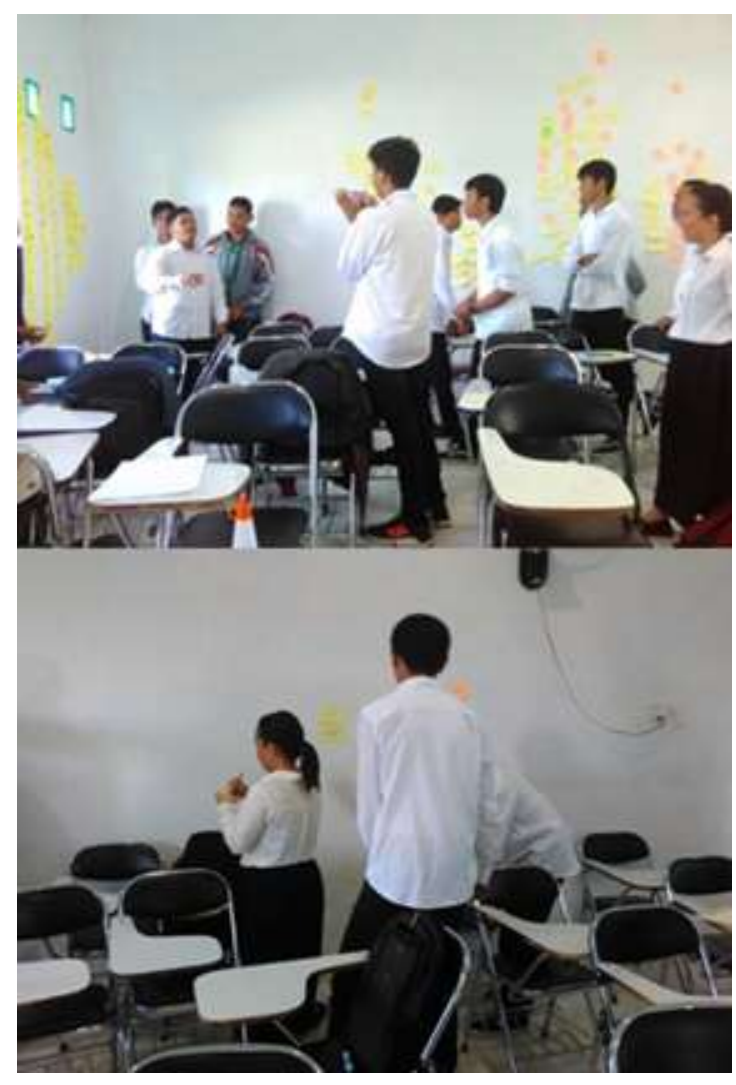

Gambar 13. Proses pengumpulan masalah

Pada Gambar 13 dapat dilihat proses pengumpulan masalah-masalah yang sangat berkaitan dengan kejadian di sekolah selama melakukan observasi dan wawancara. Permasalahan utama adalah satu permasalahan yang akan dijadikan landasan untuk langkah penentuan solusi, dalam tahapan ini akan dilakukan proses pengerucutan masalah, dimulai dengan pengelompokan masalah dan selanjutnya dipilih satu masalah saja, lihat Gambar 14. Proses diskusi bersama sesama anggota kelompok dengan saling memberikan penjelasan terhadap masalah yang akan dijadikan masalah utama diperlukan untuk mendapatkan informasiinformasi yang belum dapat disampaikan pada tahapan sebelumnya. Adapun permasalahan utama dari penelitian ini adalah kedisiplina didalam melaksanakan tugas merapikan dan membersihkan ruangan kelas.

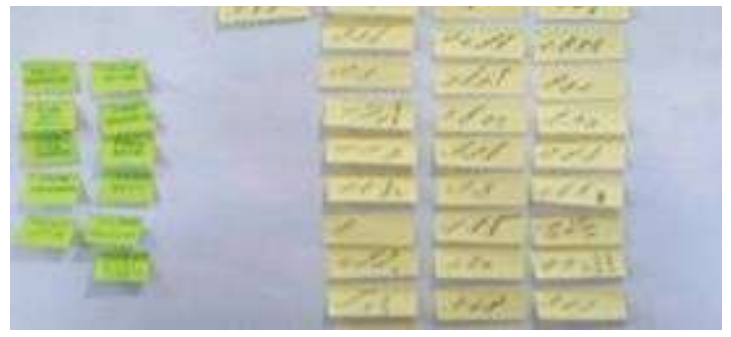

Gambar 14. Proses pengerucutan masalah untuk mendapatkan masalah utama

Tahapan curahan gagasan solusi dari masalah utama dapat dilakukan setelah menemukan permasalahan utama. Dalam tahapan ini disampaikan beberapa konsep solusi bersama anggota peneliti lainnya. Konsep solusi dapat dilakukan dengan mempergunakan peralatan menulis yang dituangkan kedalam sketsa ataupun tulisan. Pada Gambar 15 menampilkan konsep solusi utama berupa Gelang Piket.

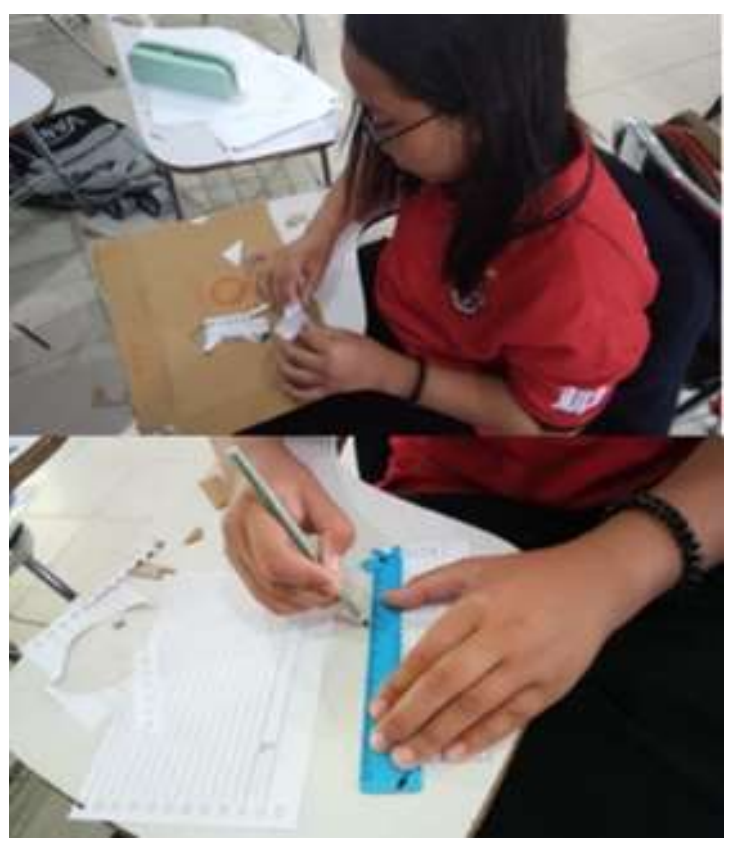

Gambar 15. Konsep solusi 


\subsection{Purwarupa}

Tahapan yang sudah mulai memerlukan pembiayaan adalah tahapan pembuatan purwarupa. Dalam tahapan awal pembuatan purwarupa, sangat dianjurkan untuk mempergunakan bahanbahan yang murah dan mudah didapatkan.

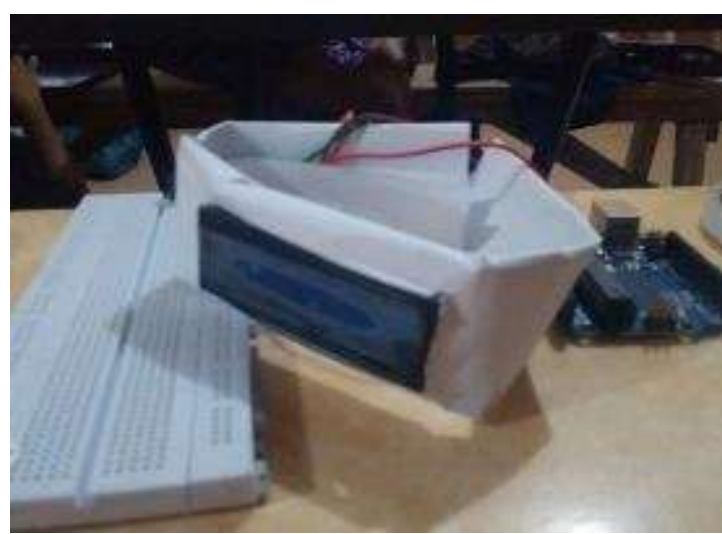

Gambar 16. Purwarupa Sederhana

Hal ini bertujuan untuk memberikan kemudahan kepada rekayasawan untuk merubah rancangan apabila nantinya di perlukan..Purwarupa dalam tahapan ini lebih dikenal dengan istilah low resolution prototype [11]. Dapat dilihat pada Gambar 16 adalah sebuah purwarupa sederhana dari Gelang Piket.

\subsection{Pengujjian Kegunaan}

Pengujian kegunaan adalah proses evaluasi terhadap inovasi yang dirancang dengan berbasis pengguna. Pada tahapan ini pengguna akan berpartisipasi dan berinteraksi secara langsung dengan purwarupa sederhana yang dihasilkan dari proses sebelumnya. Pada Gambar 17 menampilkan pengujian kegunaan purwarupa.

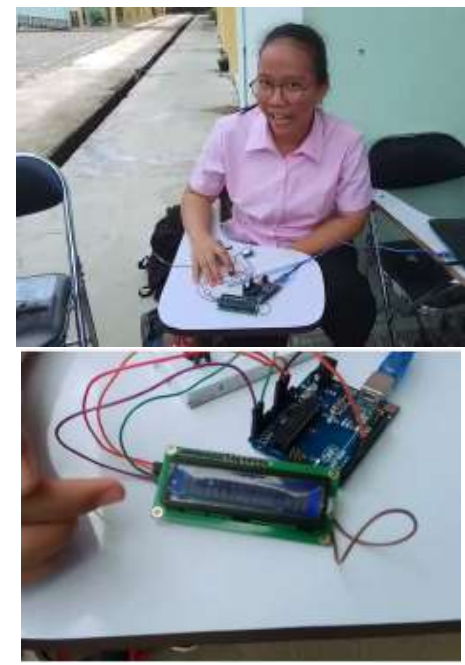

Tahapan

awal

pengujian

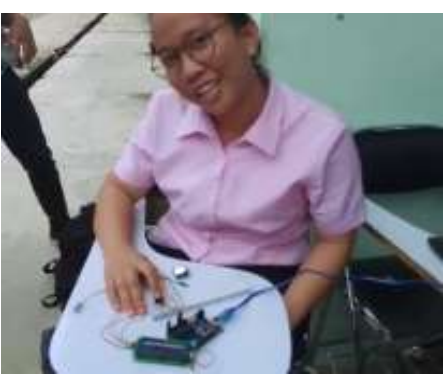

Buzzer

pengingat

juga

berbunyi

Gambar 17. Pengujian kegunaan

\subsection{Program pada Arduino}

Di bawah ini adalah program yang ditulis pada Arduino untuk dapat menghasilkan luaran sesuai yang di inginkan pada Gelang Piket.

Penjelasan tentang program :

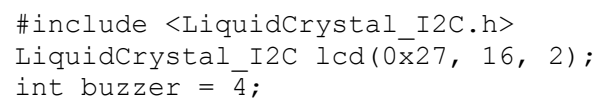

Gambar 18. Inisialisasi dan memasukan library komponen.

Pada Gambar 18 menjelaskan bahwa pada purwarupa ini menggunakan LCD 16x2 lengkap dengan serial interface I2C dan jika kita menggunakan I2C maka kita harus mengetahui dulu alamat I2C yang kita gunakan agar saat di masukan ke dalam program tidak terjadi eror, 
penggunakan I2C sangat bagus jika kita menggunakan LCD 16x2 karena dapat mengatasi permasalahan LCD 16x2 yang selalu eror.

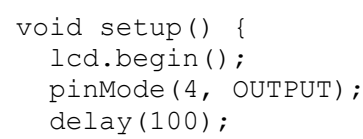

Gambar 19. Mengatur input dan output di void setup.

Gambar 19 menjelaskan bahwa dalam sketch program pada purwarupa ini diatur pin 4 pada arduino sebagai output dengan delay 1 detik, satuan detik yang digunakan di dalam program adalah microsecond.

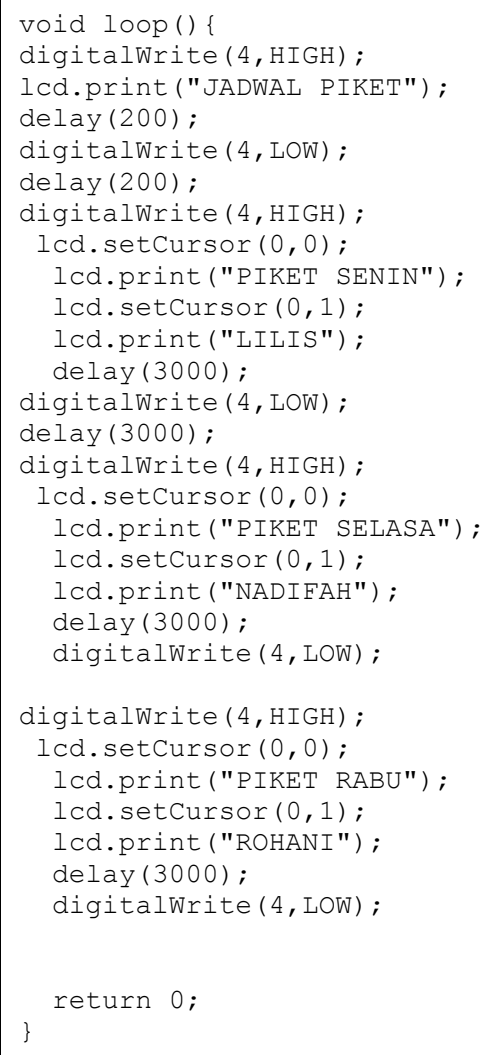

Gambar 20. Void loop fungsi perulangan pembacaan sketch program.
Pada Gambar 20 menjelaskan bahwa dalam program ini memiliki 1 output ialah buzzer yang berada di pin 4 arduino uno. Saat LCD 16x2 menampilkan text monitor "jadwal piket" dan "piket hari senin" "lilis" maka buzzer akan menyala sebagai output untuk menandai bahwa yang piket hari ini adalah lilis sesuai nama dan jadwal yang di tampilkan text monitor oleh LCD 16x2 tersebut. Dan berikut nya LCD akan menampilkan text monitor untuk menampilkan urutan piket berikutnya yaitu "piket selasa" "nadifa", dan begitulah cara kerja dari perulangan di sketch program ini terus menerus, void loop akan membaca berulang kali program tersebut.

\section{DAMPAK DAN MANFAAT KEGIATAN}

Pengguna akan diminta untuk melakukan tugas tertentu atau hanya menjelajahinya secara bebas, sementara perilaku pengguna diamati dan dicatat untuk mengidentifikasi kelemahan desain yang menyebabkan kesalahan atau kesulitan pengguna. Selama pengamatan ini, Setelah kelemahan desain telah diidentifikasi, rekomendasi desain diusulkan untuk meningkatkan kualitas ergonomis produk [12]. Tahapan proses tersebut disebut dengan pengalaman pengguna (user experience). Pada Tabel 1 menampilkan hasil pengujian dengan calon pengguna pertama. Bentuk purwarupa yang menyerupai sebuah jam tangan memudahkan siswa untuk mengingat tugasnya. Selain itu, inovasi ditemukan juga menarik karena memiliki fungsi pengingat yang sederhana. 
Tabel 1. Hasil pengujian dari calon pengguna pertama

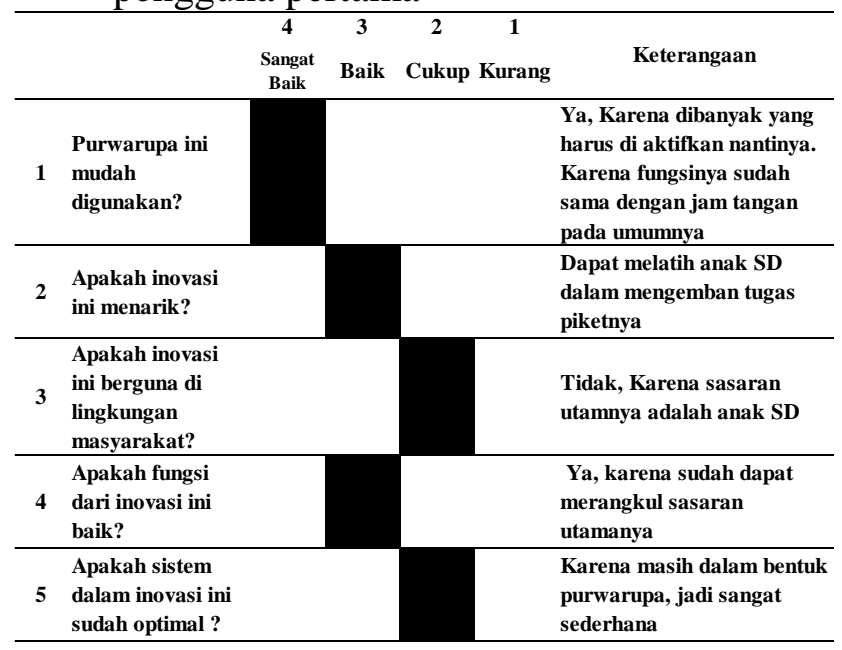

Sedangkan pada Tabel 2, menampilkan hasil pengujian dari calon pengguna kedua. Calon pengguna menemukan bahwa bentuknya yang berupa jam tidak mengganggu siswa karena siswa pada umumnya menggunakan jam tangan ketika berada di sekolah. Selain itu, fungsi pengingat akan mampu menyadarkan siswa terkait tugas piketnya, dimana pada kondisi sebelumnya siswa sering pulang karena terlupa bahwa pada hari tersebut adalah tugas membersihkan ruangan.

Tabel 2. Hasil pengujian dari calon pengguna kedua

\begin{tabular}{|c|c|c|c|c|c|}
\hline & 4 & 3 & 1 & \multirow[b]{2}{*}{ Keterangaan } \\
\hline & & $\begin{array}{c}\text { Sangat } \\
\text { Baik }\end{array}$ & Baik & Cukup Kurang & \\
\hline 1 & $\begin{array}{l}\text { Purwarupa ini } \\
\text { mudah } \\
\text { digunakan? }\end{array}$ & & & & $\begin{array}{l}\text { Karena Prototype ini simpel } \\
\text { untuk anak SD }\end{array}$ \\
\hline 2 & $\begin{array}{l}\text { Apakah inovasi } \\
\text { ini menarik? }\end{array}$ & & & & $\begin{array}{l}\text { Karena sekaligus dapat } \\
\text { menjadi hiasan tangan }\end{array}$ \\
\hline 3 & $\begin{array}{l}\text { Apakah inovasi } \\
\text { ini berguna di } \\
\text { lingkungan } \\
\text { masyarakat? } \\
\end{array}$ & & & & $\begin{array}{l}\text { Karena ini cenderung } \\
\text { digunakan untuk anak SD }\end{array}$ \\
\hline 4 & $\begin{array}{l}\text { Apakah fungsi } \\
\text { dari inovasi ini } \\
\text { baik? }\end{array}$ & & & & $\begin{array}{l}\text { Dapat membantu tugas } \\
\text { para murid SD }\end{array}$ \\
\hline 5 & $\begin{array}{l}\text { Apakah sistem } \\
\text { dalam inovasi ini } \\
\text { sudah optimal ? }\end{array}$ & & & & $\begin{array}{l}\text { Karena masih dalam bentuk } \\
\text { prototype, jadi sangan } \\
\text { sederhana }\end{array}$ \\
\hline
\end{tabular}

Hasil pengujian menunjukkan purwarupa berfungsi dapat dengan baik dan memenuhi kebutuhan calon pengguna, di dalam peneltian ini adalah siswa di sekolah dasar. Purwarupa membantu mengingatkan siswa sebelum pulang untuk melakukan tugas piket, sehingga guru tidak perlu memberikan informasi mengenai jadwal piket sebelum pulang dan melakukan pengawasan secara langsung terhadap siswa. Selain manfaat tersebut, Gelpi akan mampu menumbuhkan sikap bretanggung jawab dan saling bekerjasama sesama siswa untuk satu tujuan yang sama, yaitu kebersihan kelas.

Pengalaman pengguna akan memperluas pandangan tentang interaksi produk dengan pengguna dari aspek emosional. Adapun motivasi dari proses pengalaman pengguna adalah untuk mengembangkan pengalaman dan emosi positif. Oleh karena itu, produk harus memenuhi kebutuhan psikologis dan motif pelanggan [13].

Inovator yang berbasiskan teknologi sangat sadar bahwa kesuksesan hasil inovasi tidak hanya dilihat dari manfaat dari produk yang akan dihasilkan namun juga perlu memperhatikan faktor pengalaman pengguna., sehingga pengembangan inovasi teknologi tidak lagi hanya tentang mengimplementasikan fitur dan menguji kegunaannya, tetapi juga tentang mendesain produk yang menyenangkan dan mendukung kebutuhan dan nilai-nilai dasar manusia. Dengan demikian, pengalaman pengguna dalam tahapan Proses Desain Rekayasa harus menjadi perhatian utama pengembangan produk [14]. 


\section{KESIMPULAN}

Gelpi adalah purwarupa sederhana yang dapat membantu para siswa yang duduk dibangku Sekolah Dasar dalam mengemban tugas tambahannya di sekolah, yaitu tugas membersihkan dan merapikan ruangan kelas. Dari hasil pengujian bersama calon pengguna, didapatkan bahwa purwarupa yang berbentuk seperti jam tangan tidak mengganggu siswa, karena siswa pada umumnya sudah mempergunakan jam tangan ketika di sekolah. Fungsi pengingat sangat membantu siswa menghindari kelupaan terkait jadwal piket. Dan pada ahirnya tugas guru akan menjadi lebih mudah karena tidak perlu mengingatkan siswa setiap hari setelah jam pelajaran terahir.

Pembuatan purwarupa ini diharapkan dapat mengingatkan para siswa akan tugas tambahan, sehingga para siswa tidak lalai lagi akan tugas tersebut. Pembuatan purwarupa ini juga sangat sederhana dengan harapan akan mampu memberikan gambaran sederhana dalam bentuk Gelpi. Sehingga menjadi pertimbangan dalam pengembangan fungsi lain nantinya.

Selain itu juga dapat disimpulkan, bahwa Gelpi telah memperkenalkan digitalisasi kepada siswa dan siswa sekolah dasar melalui inovasi berbasiskan teknologi yang bermanfaat bagi sekolah, dan membentuk karakter siswa yang mampu bekerjasama dan bertanggung jawab, dimana merupakan pondasi dasar untuk generasi yang mampu bersaing di era digital revolusi industri 4.0

Pengembagan GELPI ke depannya dapat lebih sempurna dengan menggunakan komponen lebih kecil, mengingat bentuk gelang di tangan pada umumnya adalah kecil. Dan supaya GELPI dapat lebih nyaman digunakan dan tidak mengganggu aktivitas penggunanya.

\section{DAFTAR PUSTAKA}

[1] Sanyoto, I., Wibowo, A., dan Agustine, L, (2014), Reminder Kit Secara Wireless Berbasis Mikrokontroler AVR, Jurnal Widya Teknik, Universitas Katolik Widya Mandala Surabaya, Vol 13, No 2, pp. 33-44

[2] Setiwan, E., (2015), Aplikasi Alarm Anti Maling Berbasis Mikrokontroler AT Mega 8535, Jurnal SISFOKOM, STMIK Atma Luhur, Vol. 04, No. 02, pp. 28-34

[3] Muzaki, A., S., Hendra, A, and Pamungkas, W., (2011). Aplikasi Sensor Cahaya Untuk Alaram Anti Pencuri, Jurnal Infotel, Institut Telkom Purwokerto, Vol. 3, No. 2

[4] Irjayanto, S., Chamim, A.,N., N., (2015). Prototipe Kotak Pengingat Minum Obat, Jurnal Ilmiah Semesta Teknika, Universitas Muhammadiyah Yogyakarta, Vol. 18, No. 2, pp. 182-189.

[5] Kastner, S and Knight, R. T, (2017), Bringing Kids into the Scientific Review Process. Neuron, Vol. 93, Edisi 1, page 12-14, Elsevier Inc

[6] Irbīte, A., and Strode, A.,(2016), Design thinking models in design research and education, Proceedings of the International Scientific Conference. Vol. IV, page 488-500 
[7] A Scottish approach to designing public services A Scottish approach Design approach [Daring], Tersedia pada : https://resources.mygov.scot/37f87d 5/designing-public-services-inscotland/why-we-need-design-forpublic-services-in-scotland/designapproach/ [Diakses : 31 Mei 2019].

[8] Stanford University [Daring], Tersedia pada : http://web.stanford. edu, [Diakses : 31 Mei 2019]

[9] Sekolah Kita [Daring], Tersedia pada:

http://sekolah.data.kemdikbud.go.id/ index.php/chome/profil/90AD19BD -31F5-E011-B7F8-3B12490BB869 [Diakses : 31 Mei 2019].

[10] Wagner, C., Kawulich, B., and Garner, M., (2012), Collecting Data Through Observation, Doing Social Research: A global context, McGraw Hill

[11] Nusyirwan, D., (2017) Engineering Design Process Engineering Student Centered Experience Learning (ESCEL) di Jurusan Teknik Elektro Universitas Maritim Raja Ali Haji (UMRAH).

[12] Bastien, J.M. C., (2010) Usability testing: a review of some methodological and technical aspects of the method", International Journal of Medical Informatics, Vol. 79, Edisi 4, page e18-e23, Elsevier Ireland Ltd

[13] von Saucken, C., Lachner, F., and Lindemann, U., (2014), Principles for User Experience What We Can Learn from Bad Examples,
International Conference on Kansei Engineering \& Emotion Research

[14] Johnson, G. I., Clegg, C. W., and Ravden, S. J (1989), Towards Practical User Experience Evaluation Methods, Applied Ergonomics, Volume 20, Edisi 4, p. 255-260, Elsevier Ltd 